\title{
Innovative training strategy for higher education: the photonics training platform at University of Bordeaux
}

\section{Marie Bénédicte Vieules, Jean Oberlé, Eric Cormier}

Marie Bénédicte Vieules, Jean Oberlé, Eric Cormier, "Innovative training strategy for higher education: the photonics training platform at University of Bordeaux," Proc. SPIE 10452, 14th Conference on Education and Training in Optics and Photonics: ETOP 2017, $104521 Z$ (16 August 2017); doi: 10.1117/12.2266354

SPIE Event: 14th Conference on Education and Training in Optics and Photonics, ETOP 2017, 2017, Hangzhou, China 


\title{
Innovative training strategy for higher education: the photonics training platform at University of Bordeaux
}

\author{
Marie Bénédicte Vieules, Jean Oberlé, Eric Cormier - University of Bordeaux, France \\ marie-benedicte.vieules@u-bordeaux.fr
}

TOPIC: New pedagogical methods, tools and models in optical education

\begin{abstract}
The Photonics training platform of University of Bordeaux aims at renewing higher education offer by structuring training (initial and continuing) on a «sector-specific » approach. The initiative is organized around key professional sectors identified in collaboration with regional socio-economic partners as well as research and teaching teams from Bordeaux's higher education facilities.

The training platform intends to improve the hiring potential of students through a better match between the initial training courses and the labor market needs and to develop lifelong training courses in the University of Bordeaux. It aims at organizing these courses according to an approach by field and to establish their position at national and international levels.

The platform acts on three priority axes: training provision, national and international partnerships, pedagogical innovation as well as lifelong learning improvement. Its strategy is based on the latter priorities and consists in the development of the training offer on the application sectors in close connection with industrials and a significant involvement in internationalization.

The Photonics training platform strives to become a collaborative lab of ideas to design innovative learning tools by revisiting teaching methods in relation with technological developments; create a community of education experts in the field of photonics to spread this key enabling technology around scientific thematic taught in university.

This project provides resources available to all stakeholders for better efficiency in the design and management of training projects and will be engaged in a continuous improvement process to establish the continuity of projects and quality enhancement.
\end{abstract}

Keywords: lifelong learning, innovative learning tools, teaching methods, photonics.

14th Conference on Education and Training in Optics and Photonics: ETOP 2017, edited by Xu Liu,

Xi-Cheng Zhang, Proc. of SPIE Vol. 10452, 104521Z · @ 2017 ICO, IEEE, OSA, SPIE

CCC code: $0277-786 \mathrm{X} / 17 / \$ 18 \cdot$ doi: $10.1117 / 12.2266354$

Proc. of SPIE Vol. 10452 104521Z-1

Downloaded From: https://www.spiedigitallibrary.org/conference-proceedings-of-spie on 26 Apr 2023 Terms of Use: https://www.spiedigitallibrary.org/terms-of-use 


\section{INTRODUCTION}

In 2010, the French government launched the "Investment for the Future" State program. In 2016, the University of Bordeaux is one of the three French universities confirmed in this program. The initiative of excellence (IdEx) Bordeaux is a dynamic of long-term growth and development in higher education and research activities based on three fundamental challenges: excellence of research, innovative training and outstanding transfer of knowledge.

The Optics, photonics and laser training platform is part of the IdEx Bordeaux Innovative Training program (Bordeaux Excellence Investment).

The photonics platform aims to structure the Bordeaux training offer in the photonics sector in order to improve the integration of students and optimize the competitiveness of the companies in this sector by improving general photonics skills.

The platform's actions focus on 3 main topics:

- Developing lifelong training in the photonics sector, by adapting to technological changes and the needs of socio-economic players with the development of the training offer by photonics applicative market sectors;

- Developing a network of industrial and academic partners beyond the Bordeaux campus to increase the outreach of the training offer and boost its attractiveness: joint curricula, an European strategic partnership (Erasmus+ program)

- Stimulating apprenticeship through innovation by bringing together partners and ideas in a "laboratory" of educational practices by creating innovating learning tools (serious game, digital application).

The program is based around initiatives for educational innovation, internationalization and the suppression of barriers between different educational formats. It requires also a high degree of synergy with socio-economic partners, made possible by close collaboration with professional and industrial experts.

After four years of existence, the platform has entered a phase of development and is part of the overall policy of the University of Bordeaux.

\section{RENEWING HIGHER EDUCATION AND RESEARCH: A CHALLENGE FOR UNIVERSITY OF BORDEAUX}

The University of Bordeaux is ranked among the top universities in France and is internationally renowned for the quality of academic courses, research and an exceptional quality of life. With the mergers of 3 of the universities, in 2015 , into a unified institution, the university has put forth an aspiring vision: to be one of the top research driven universities in the world.

In its $\mathrm{U} 25^{1}$ development plan, the University of Bordeaux proposes a strategic vision to decline for the next few years. The approach is to address some of the key challenges facing society today. It positions University of Bordeaux talent, programs, potential and outcomes to have a broader reach with significant impact, so that the university can be better positioned to help change and shape the world for the better, both today and in the future. By focusing on providing excellent education, creative learning environments and the tools to transform knowledge into meaningful solutions, University of Bordeaux aims to empower their students to succeed in a global society that is fast and ever changing.

\footnotetext{
${ }^{1}$ http://www.u-bordeaux.fr/Universite/Grands-projets/U25
} 


\section{Idex Program}

The University of Bordeaux is one of the three French universities, awarded with the "Initiative d'Excellence" program (IdEx)", a French massive investment program for research and higher education that have seen their investment program for the future confirmed in 2016. This program, launched in 2010 is intended to finance what will make the strength of France of tomorrow. Higher education and research have been identified as key priorities with $€ 22$ billion dedicated over ten years. The Excellence Initiative of the University of Bordeaux (IdEx Bordeaux) implements innovative programs for research, training and knowledge transfer in close collaboration with research organizations and partner institutions. These programs are financed by revenues from a $€ 700$ million grant to IdEx Bordeaux and should be complemented by investments from partners and external resources.

The IdEx Bordeaux program addresses three fundamental challenges: innovative research, training and knowledge transfer. The University of Bordeaux and its partners intend to support this effort by creating a Campus of Excellence with an international outreach, bringing together key research players in cutting-edge scientific fields such as neuroscience, technologies for health, public health, materials of the future, environment/climate, archeology, opticsphotonics-laser and informatics/certification.

This program is divided into several axis: meeting the research challenges, focusing on talents, creating tomorrow's innovative courses, promoting student empowerment, building an international outreach and a better connection with society.

The educational section of the IdEx programme ${ }^{2}$ aims for preparing students for today's and tomorrow's career requirements. IdEx Bordeaux invests in the constant renewal of its full-time and lifelong training programs. This renewal is based on three sections: Innovation in Education, International Master's Degrees and Training Platforms programs.

The Innovation in Education program main objective is to support the development of an innovative range of courses for the new 2016-2020 accreditation. The supported projects are those aimed at diversifying teaching methods, which can be reproduced on a large scale and transferred to other disciplines. The two priority focuses are digital and international projects. The International Master's Degrees program develops a high-quality international offer to bring in promising international students and increase the competitiveness of international consortia and are supported either in the launch or development phases.

The Training Platforms program objective is to develop a full-time and lifelong training offer in key regional fields which are competitive on the European scale. The projects supported are in selected fields having demonstrated their regional potential, as well as their international development prospects. Four fields are covered: forestry and timber, optics-photonics-laser, aeronautics, ocean. This initiative also aims to break down barriers between different educational formats. It is backed by close collaboration with industrial partners. IdEx Bordeaux invests in the constant renewal of its full-time and lifelong training programs. This renewal is based on the innovation in education, international curricula and partnerships. For the Photonics platform, the renewal of the training offer consists in disseminating photonics within every engineering branches taught in the campus. This initiative also aims at breaking down barriers between different educational formats. It is strengthened by close collaboration with industrial partners.

Two support programs complete the educational section of the IdEx program: The International Challenge is a program which offers educational and linguistic support for the development of teaching in English. The Support for Innovation in Education Initiative (MAPI) offers support to the academic teams of the University of Bordeaux for the development of courses and teaching methods.

\footnotetext{
${ }^{2}$ http://idex.u-bordeaux.fr/n/Innovative-courses/r3003.html
} 


\section{Optics-photonics-laser training platform}

The ambition of the training platforms is to structure an innovative training offer paying special attention to lifelong learning. The challenge is to prepare students for a better professional integration but also by a skill-building for professionals within their company.

The strategic objective of the Photonics training platform is to disseminate photonics skills in all application sectors of this Key Enabling Technology ${ }^{3}$. The objective of the photonics training platform is to expand Bordeaux's educational offer across the entire photonics sector by creating links between initial and continuing education, educational innovation projects and international initiatives. The challenge is to create an interdisciplinary training offer built with a plurality of stakeholders: higher education institution, competitiveness cluster, industrials, socio-economics stakeholders.

\section{PROJECT PHASE}

\section{Stakeholders}

The first phase of the Photonics training platform project lasted heighten months, from July 2013 to December 2014 to identify the stakeholders, map the existing training offer, collect the training needs and settle a strategy.

The Aquitaine area (recently renamed "New Aquitaine" area in 2016) is now the largest French region in terms of area. Bordeaux is the largest city with 850,000 inhabitants (together with its suburbs and satellite cities) and the $7^{\text {th }}$ largest metropolitan area in France. New Aquitaine is the first French region in terms of demographic dynamism and after Ilede-France, the premier French region in research and innovation with five universities: Bordeaux, La Rochelle, Limoges, Poitiers and Pau together with several "Grandes Ecoles".

New Aquitaine's economy is mainly based on agriculture and viticulture, tourism (with many companies specializing in surfing) but also on aerospace industry, digital economy and design, parachemical and pharmaceutical industries, financial sector (mutual insurance companies), and industrial ceramics.

The photonics and lasers activities have organized since 1995 around the Laser Megajoule ${ }^{4}$ (LMJ), a large research infrastructure. The LMJ, is a CEA (French Alternative Energies and Atomic Energy Commission) major installation for the French simulation program. This program is at the origin of the establishment of several companies, mainly grouped together around the competitiveness cluster ALPHA-RLH (the cluster aggregate skills in photonics, lasers, microwave and digital technologies). 250 companies have joined the cluster within five strategic domains of activities (aeronautics and space, healthcare, energy, lasers and processes, components and instrumentation).

The IOA (Institut d'Optique d'Aquitaine) building, initiated by the region Aquitaine, is a new centre dedicated to photonics. This centre gathers teaching and research spaces, industrials incubators: an initial training center (Institut

\footnotetext{
${ }^{3}$ Key Enabling Technology (KETs) are a group of six technologies that have a wide range of product applications such as developing low carbon energy technologies, improving energy and resource efficiency, and creating new medical products. They have huge potential to fuel economic growth and provide jobs. KETs comprise micro and nanoelectronics, nanotechnology, industrial biotechnology, advanced materials, photonics, and advanced manufacturing technologies. The 2009 Communication on KETs describes these further. They provide the basis for innovation in a wide range of industries such as automotive, food, chemicals, electronics, energy, pharmaceuticals, construction, and telecommunications. They can be used in emerging and traditional sectors. Because of their potential to help industry grow, KETs are a priority for European industrial policy. The European Strategy for KETs aims to accelerate the rate of exploitation of KETs in the EU and to reverse the decline in manufacturing to stimulate growth and jobs.

https://ec.europa.eu/growth/industry/key-enabling-technologies/description_en

${ }^{4}$ http://www.cea.fr/english/Pages/research-areas/defence-and-security.aspx
} 
d'Optique Graduate School and University of Bordeaux) preparing for the diplomas of engineers and master in the fields of optics, computing, nanosciences and complex systems, PYLA a continuing education center for the optical and laser professions, a research center on instrumentation, hybrid systems and augmented reality, photons and nano systems, atomic lasers and microsystems (LP2N laboratory) and an incubator centre to support young companies ALPhANOV.

\section{Research and education environment}

The analysis of the existing was the first phase of work to define the contours of the platform and the first assignment was to reference to research laboratories and the training offer for higher and continuous education.

Eleven laboratories at the university of Bordeaux are working in the field of photonics and are grouped into a cluster of excellence $^{5}$ : LAPHIA- Laser and PHotonics In Aquitaine. The challenge of LAPHIA is to develop the research in the fields of laser and high energy physics, photonics materials and innovating imaging. LAPHIA supports projects with potential for technological breakthroughs. Progress in optics and photonics plays an important role in many sectors of our society: aerospace, energy, automotive, communications, health, medical, etc. The results of research supported by LAPHIA make technological innovation possible, as well as development of new products and/or business creation.

The University of Bordeaux offers laser and optics course programs at several level, the training offer spreads into several level of training: undergraduate and graduate degrees for the College Sciences and Technology, bachelor of technology for university institute of technology (IUT) and graduate degrees for engineering schools.

Undergraduate and graduate degrees are mainly fundamental trainings on the fields of physics and chemistry, plus some training units in bioimaging course program. One specific course program (professional licence degree) delivers technicians skills: a professional undergraduate program dedicated to maintenance of laser. Several course programs are available at the IUT (physics measurement, mechanical engineering). These are two-year diploma post-baccalauréat program. These degrees are taught at university of Bordeaux.

There is also one engineering school dedicated to optics: the Institut d'Optique Graduate School a "Grande École" of engineering which is an institution of higher education and research with one of its campuses located in Bordeaux. The Bordeaux INP engineering school delivers diploma within five thematic schools. ENSCBP (Chemistry, Physics and Biology) is the most related to optics field.

Within all the campus, at least 60 taught modules are related to optics. There are some modules in physics, chemistry, biology and health, engineering sciences, but also in mathematics, archeology, architecture, arts. The map of training allows a potential leverage of this technology within several fields. The map of training induces the strength and potential leverage effect of this technology within several fields.

The University of Bordeaux is also involved in a training center in optics and photonics for continuous education named PYLA. PYLA is a consortium between the University of Bordeaux, CEA and the competitiveness cluster ALPHA-RLH. Its role is to provide and develop short training courses for industrials. Since its creation, PYLA has developed a training offer by pooling the resources and skills of its founders and developing new partnerships to create a unique catalog, a portal for continuing education in photonics, optics and laser. PYLA offers more than 40 training courses on the different topics of lasers, optics, photonics and their applications. PYLA has been designed to support the development of the laser optical sector in Aquitaine as continuing education plays an important role in developing technologies for markets with photonics applications, by educating integrators and users.

The following action was to draw an analysis of the needs and requirements by meeting every stakeholder and collect their needs in terms of training offer. One of the Photonics training platform challenge is to renew the training offer to the path of photonics technology. The map of the offer has been completed with the map of the needs. These needs are especially drawn by the industrials development and expectation. For example, in the aerospace industry, laser

\footnotetext{
${ }^{5}$ LAPHIA is an IdEx Bordeaux research program for strengthening research linked to different sites' federal projects through the support of its teams of excellence working in physics and material sciences
} 
technology is now commonly used for communication, machining, assembly, non-destructive testing. But the photonics technology for this application sector is not taught at the university yet.

This process of gathering needs continues in a process of constant market evolution. The model of the platform aims at an evolution and the possible opening to any new potential stakeholder.

A study carried out from February to July 2015 categorized needs assessment as well as a definition of the scientific potential and the opportunities for development of the offer on all the fields of engineering.

This work consisted of:

- the identification of the training and Educational Units of training of photonics in chemistry, biology, earth sciences and engineering sciences

- bringing together leaders and teachers of such units in order to gather their needs in skills in photonics

- a benchmark by industrial application sector

- a benchmark of photonics department at international level.

At the end of this study, a working group of teachers and researchers from the Physics department met in May 2015 to propose and prioritize actions to be developed during the academic year 2015-2016.

\section{Project Development}

The conclusion of the strategic analysis phase was to propose to develop and extend the photonics training offer to the applicative sectors of this technology, such as aeronautics, health and medicine, engineering, energy, light, etc. The aim of the University of Bordeaux is to train all students registered in an "engineering" domain to acquire photonics skills.

The strategic issues are then to create a photonics field-oriented and interdisciplinary training offer in photonics, rather than a thematic training, such as physics or chemistry. The structure of this training offer is conceived as a continuum of lifelong learning with a network of mutualization between initial and continuing education. The development criteria for the platform need to meet the market needs create partnerships, disseminate photonics within every engineering thematic with large « applicative sectors » potentials. The training platform accompany innovative projects designed by teachers.

The Photonics platform's actions lean on three main focuses:

- Developing lifelong training in the photonics sector, by adapting to technological changes and the needs of socio-economic players

- Developing a network of industrial and academic partners beyond the Bordeaux campus to increase the outreach of the training offer and boost its attractiveness

- Stimulating apprenticeship through innovation by bringing together partners and ideas in a "laboratory" of educational practices

The orientations for the Photonics platform are as follows:

- A community for photonics training with a diffusing effect on all engineering sector: the platform is a community that brings together expertise from all the themes of photonics and mixes learners, teachers and professionals

- A structuring of the supply of training on a sector: the training offer finds its coherence in the pooling of initial and / or continuous training

- A service center for all stakeholders: a meeting point for an increase in skills and effectiveness in project design and management

- A laboratory of projects to develop new educational practices: a collaborative laboratory of ideas and practices to design educational tools and to evolve the learning modalities in line with technological evolutions 
- A coherent lifelong learning path: continuity in training throughout the career with a continuous interaction with the needs and practices of the company.

- An iterative process of continuous improvement: a long-term commitment to ensure project continuity and quality enhancement

The Photonics platform project started in July 2013 and its actions were initially centered on the Physics Department, PYLA and LAPHIA. In view of the strategic analysis and the orientations defined by IdEx, the platform is opening in its phase of development to several other actors of the training in photonics of the Bordeaux campus in order to develop training projects for the benefit of the whole photonics community, in biology, health, imaging, engineering sciences.

After an initial period of pilot projects operation, the training platform is now in the development phase and has adopted a governance with two committees, a steering committee and a pedagogical committee.

The steering committee validates the strategy and its orientations:

- Defines the strategic framework for the actions of the platform

- Verifies the execution of the project as a whole

- Conducts a global review of the projects proposed by its partners and verifies their suitability for the targets (students and companies)

- Validates the activity report and the strategic action plan

- Facilitate the achievement of the objectives of the platform between partners

The steering committee is made up of directors of training components from the University of Bordeaux, directors of engineering schools on the Bordeaux campus, representatives of the Bordeaux university presidency, the education director of LAPHIA.

The pedagogical committee, composed of referent resources from each scientific component, defines the strategic action plan, proposes projects that are consistent with the strategic orientations, evaluates the pedagogical relevance of the projects and monitors the projects

A project team, in charge of the strategy of the Photonics platform, is centered around teacher-researchers and vocational training experts who contribute to the development of training offer and pedagogical relevance. The coordination is carried out by a project manager recruited the University of Bordeaux. A scientific consultant (university physics professor) certifies the global relevance of the projects.

An operating budget is financed by IdEx. This budget covers the salary of a project manager, the incurring fees related of the accompanying of the project by professors-researchers, the operating costs of communication type, logistic organization of events. Projects are funded through the IdEx global training program and co-financing through calls for projects.

\section{DEVELOPMENT AXIS OF THE PLATFORM}

\section{Training}

The strategic direction for this axis is to develop and structure the training offer to the applicative sectors of photonics. This orientation is divided into several actions to improve the visibility of photonics at the Bordeaux campus (workshops), development of the training offer (Inter-university diploma in dentistry), the introduction of photonics into existing or future courses (Dual health \& sciences curriculum), the availability of a teaching desk dedicated to practical works (BTS photonics). 
The ambition of the project is to increase the knowledge and skills in photonics of the students of the scientific branches of the University of Bordeaux:

- Responding to training needs for the future (prospects for industrialists)

- Develop training programs based on existing modules in initial and continuing training

- Mutualize lessons between several disciplines

- Optimize the use of the teaching desk for practical work in other scientific fields

- Create new initial and continuing training.

The aim of deploying the training offer on the applicative sectors of photonics is to spread knowledge of photonics more widely, to develop skills among students in all the engineering sectors present on the Bordeaux campus and to generate a need for training in companies. Several projects and arrangements have been put in place.

Training sessions on the applicative sectors of photonics are offered to a mixed public of students and industrialists to give a first training / information on this diffusing technology. The aim is to offer sessions to acquire new skills and to consolidate the general scientific knowledge in the field of photonics. The challenge is to attract students to the photonics sector and to support exchanges between industrialists and academics in disciplines and courses with strong potential for innovation. Each 90-minute session features 40-minute introductory presentations by teachers for the scientific theoretical part and 40 minutes by industry to present industrial applications of these technologies followed by a discussion time with the public. The audience is meanly composed of students in physics but also in the sciences of engineering, humanities, architecture, civil engineering, earth sciences, engineering students and industrial according to themes. The challenge is to further disseminate the training offer to the other areas taught at the university and to produce a catalog of either EU-wide training courses, short courses or the establishment of university diplomas.

The Inter-university diploma in laser and dentistry delivers a diploma for dentists and dental surgeon. It provides the scientific and technical knowledge required for laser practice in applications in dentistry and dental surgery, the use of lasers under optimal safety conditions and informs about the latest technological developments of lasers to allow a critical analysis of their applications. This postgraduate diploma, awarded as part of initial training for interns in dentistry and continuing education for practitioners.

In September 2017, a double health and sciences curriculum will open to students from the medical, pharmacy and dentistry sectors who are selected at the second year entrance to general health education. The aim is to promote biomedical innovation while shortening the time between scientific innovations and clinical applications. The pedagogical path will be affiliated with the College of Health, in collaboration with the Colleges of Science and Technology and Human Sciences.

A photonics training program dedicated to biologists is under discussion. It will develop short courses, complements of courses, distance learning, mutualization, seminars and workshops "photonics applied to ..." for a mixed public (industrialists, students ...), as well as physics workshops for biologists and practical training on the photonic training lab.

In September 2017, a two years professional degree - BTS in photonics systems will open at Kastler high school (close to the University campus). Following the feasibility study, the practical works will take place in the photonic training lab. In order to keep costs under control and benefit from its outstanding teaching equipment, practical works will be carried out in the photonic training lab, of the Physics Resources Center from the Physics Department of University of Bordeaux at the IOA. 15 to 20 hours of practical work per week will be performed on the laser teaching desk.

The next challenge will be the construction of a lifelong training path, by pooling initial and continuing training offers. The objective is to strengthen skills of professionals in optical, photonic and laser through the development of initial and in-service short training modules integrated into the curricula for initial training. New topical modules would 
complement the lectures offered in the various programs to acquire further training on a topic. The mutualization consists of a regrouping of all the modules taught in the different Educational Unit in order to create trainings on a given subject.

\section{Pedagogic innovation}

One of the challenges to be overcome for higher education is to provide accurate skills to students and teaching methods for teachers. Designing innovative learning tools is a way to achieve these requirements and spread this key enabling technology around scientific topics taught in university.

Learning photonics is challenging because it requires understanding scientific concepts, physics properties, acquires strong abstraction ability and scientific reasoning and construct mental images and schemes. Traditional learning in physics is based on face-to-face classroom teaching and practical work courses. The photonics training platform is cooperating with teachers to create and develop innovative tools. There has been tremendous progress in teaching methods and technologies in recent years. Students of the Y generation are native users of ICT technologies. Practical training of up-to-date optics and laser technologies requires expensive instruments usually exceeding the budget of training centers. Several pilot projects have led to the emergence of training tools.

MooBook, an interactive resource editor for science education provides to teachers a software capable of creating attractive resources that can be disseminated in mobile medium. The objective is to increase the student's knowledge while strengthening the university's presence in their daily lives. Such resources are able to show disciplinary interdependence and thus contribute to the interest in scientific pathways. The prototype developed is the theme of wave. This choice is linked to the recurrence of thi theme in many topics (light, sound, wave, earthquake...) and the contribution of digital technology in the visualization and understanding of the various phenomena involved. The different scientific disciplines concerned (physics, oceanography, geology, acoustics, photonics...) will be able to integrate this demonstrator in each of their lectures. The Resource Editor lets include several activities, text, photo, audio, and video content and offers several educational activities to create an interactive digital book. The demonstrator includes at most 4-5 levels with 4 to 5 pages per level. It contains explicit content, multiple choice questions, questions to be linked (with words alone or sentences), scheduling / categorization, computed questions, all organized in a "gamified" learning path: end of Levels or stages giving rise to a score and obtaining stars.
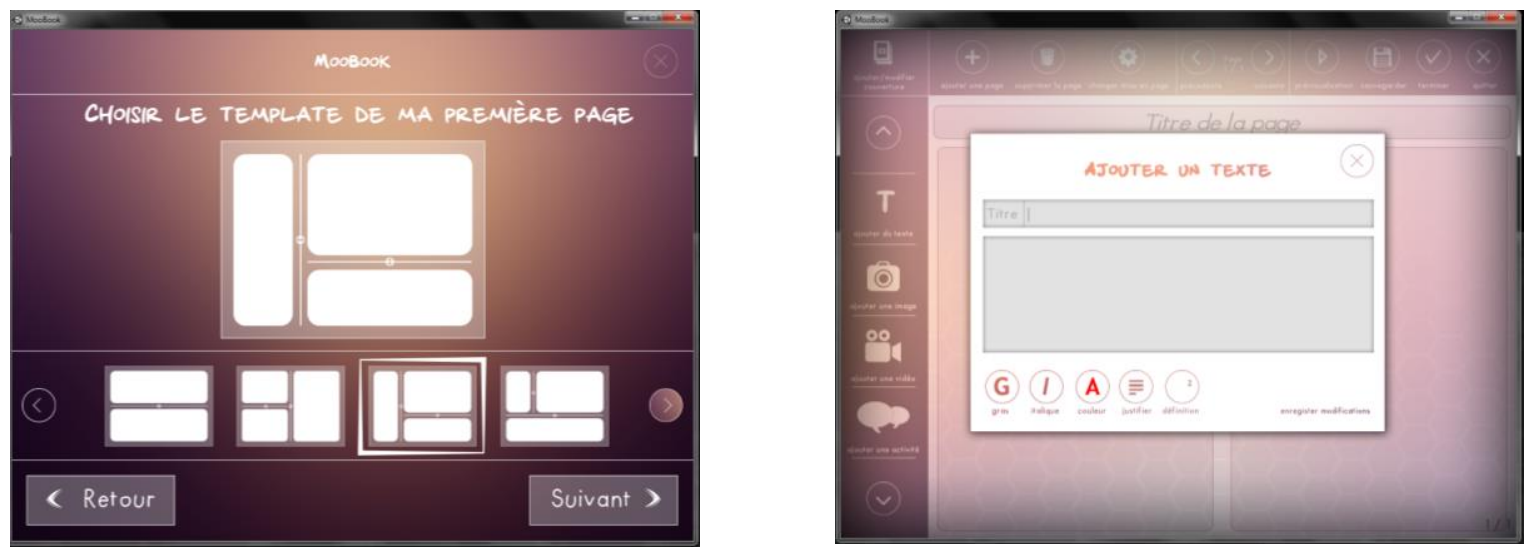

Figurel and 2. Moobook's interface for the generator 


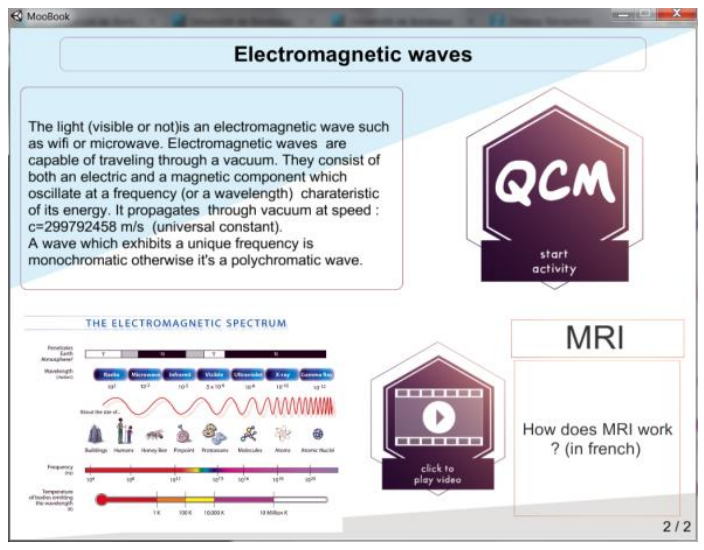

Figure 3. Moobok's interface for the reader

The Virtual Photonic Learning Lab, an immersion project based on the Oculus Rift virtual reality headset. There, the trainee is immersed in virtual full 3D laser lab where he can design, build and manipulate optical setups and lasers. The physical properties are as close as possible to reality. This serious game draws on highly advanced 3D gaming technologies to train and practice on optical and laser systems. Pedagogic scenarios have been be created to train technicians, engineers, students, and end users in maintenance, development, assembly, and alignment. Training in optic and laser technologies requires practical lessons on expensive, stationary equipment that needs high-level maintenance. This project offers real pedagogical innovation, utilizing attractive methods for learners that are more intuitive and help introduce complex concepts at low cost and without danger.

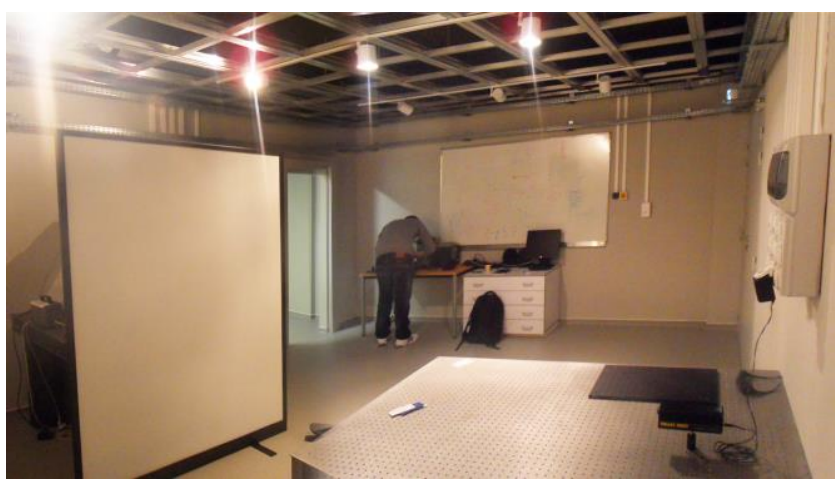

Figure 4. The real lab

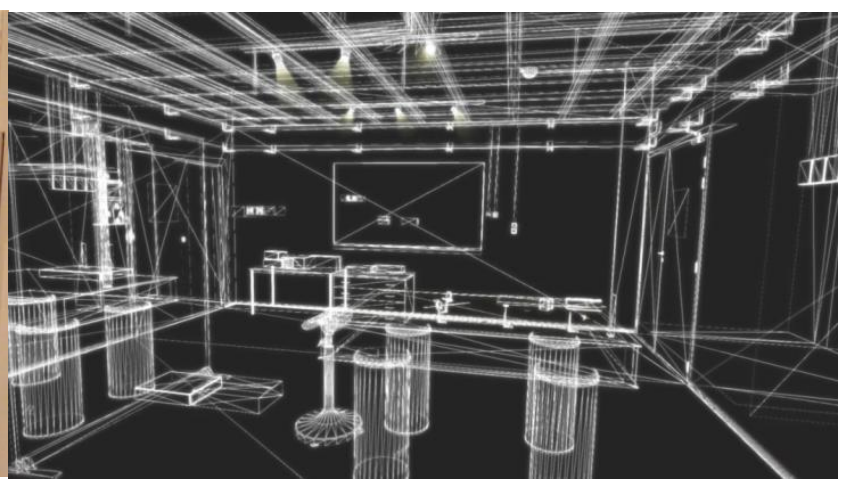

Figure 5. The virtual lab in progress

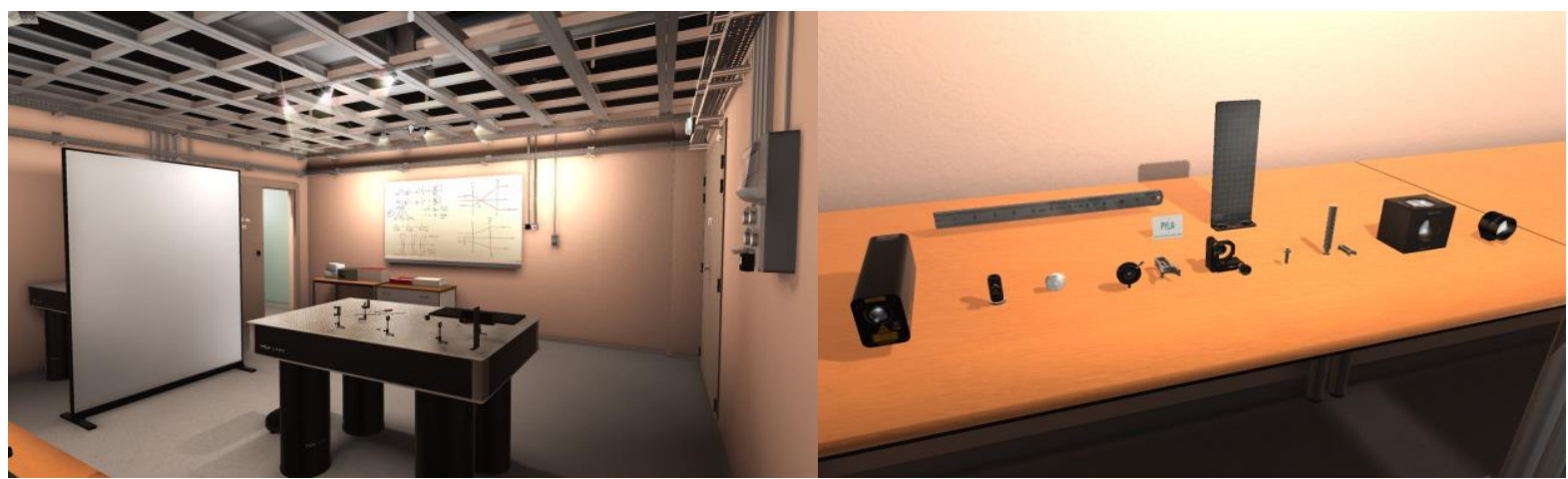

Figure 6. The virtual lab

Figure 7. The virtual optical elements 
The Hybrid optical bench for innovative training [1] is a research project. The goal is to create an optical bench with tangible interaction and validate the ability to train students with an augmented reality optical bench. The pedagogical approach is based on augmented reality (make visible the physical rules). HOBIT is a simulator and has a hybrid approach. A Michelson interferometer (used for metrology) is recreated as an Augmented Michelson Interferometer (AMI). The optics elements are 3D printed and the physics models are numerically simulated in real time on a computer. The values obtained from the potentiometers (position and orientation of the mirrors and position of the lens) modify the parameters of the simulation.

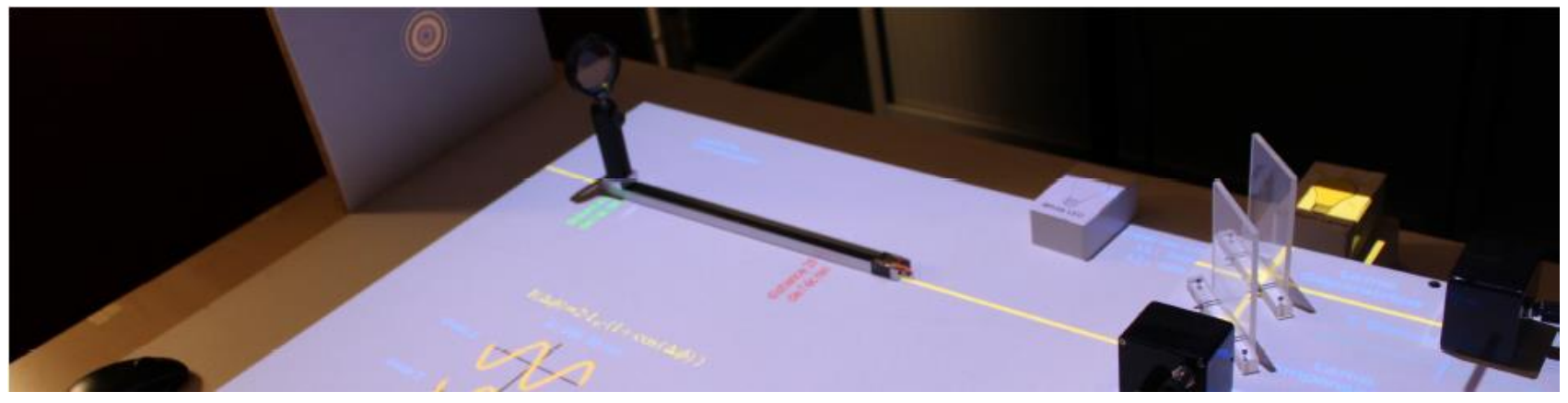

Figure 8. Simulation and augmentation of a Michelson Interferometer experiment. Physical and digital content are merged in a unique seamless environment
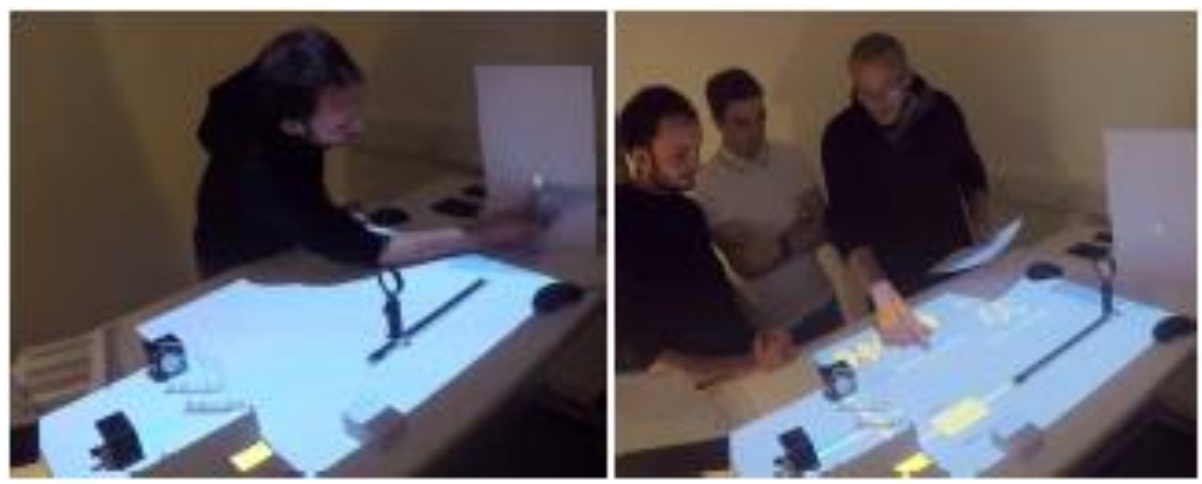

Figure 9. Example scenario. Student measures physically the period of the fringes on the projection screen. Teacher explaining the modulation of contrast.

Beyond the simulation of real optical phenomena, the system augments the workspace with digital information. This information has educational purposes or serves as guidance to users. For example, the users can see how the light travels through the elements that form AMI; it also provides information about these elements such as the current orientation angle or position. To achieve this, a mapping of the physical space is performed to ensure to the augmented space a system consistency. This information is projected using a video projector situated at the top of the setup.

The next objectives of the Photonics training platform include implementation of these new tools within license and master degree curricula. In parallel, the training platform works on a greater insertion of industrials in the design of these innovative tools to better answer their needs. The renewing of the programs goals to attract more students to science and photonics, a key technology for the future and a sector that creates quality jobs with a high level of added value for the coming years.

The photonic training lab is a pedagogical lab with an outstanding set of lasers and optical equipment only dedicated to education raising the Bordeaux training capability in photonics at the very first European level. This $1 \mathrm{ab}\left(300 \mathrm{~m}^{2}\right)$ is 
paramount in improving the employability of students and accompanying companies in the Development of their skills. The development of the photonic training lab is part of a strategy for the transfer of skills between researchers at the University of Bordeaux, PYLA partners and pedagogical board users (initial and continuing vocational training students). The transfer of skills through training ensures the dissemination of knowledge in order to achieve scientific excellence. The concentration of high-tech equipment on a single educational platform has the ambition to extend the training offer to the highest level of performance. The courses are built around a theoretical foundation and give a large part to the experiments, constantly updated in order to maintain the match with the evolving training needs of companies.

\section{International and partnership}

The third challenge is to create a network of industrial and academic partners around training in photonics. Several calls for European projects and communication actions were carried out in order to fulfill this objective.

Double diploma programs are currently being developed with exchange programs for master students in the fields of science and technology and, in particular, in the fields of chemistry and physics between the University of Bordeaux and the National Institute for Scientific Research in Canada. This project originated from a work of attraction capacity based on the LIA to recruit more students and the desire to create a master of photonics from the existing models for the University of Bordeaux. The INRS wants to create a photonics path for its students.

The strategic partnership Erasmus+ IT-ELLI, Innovative Training and Education for Large Laser Infrastructure $^{6}$ is a collaborative project of ten European partners. It proposes a roadmap with a three-year program. Each partner implements its expertise to create a community of competences between very large laser installations by improving the digital integration of learning and teaching activities through ICT-based tools. The project partners are ELI-Beamlines in the Czech Republic; ELI-Alps and the University of Szeged in Hungary, ELI-NP in Romania, Science and Technology Facilities Council in England, ELI-DC in Belgium, Ecole Polytechnique, IDSC Group, PYLA-ADERA and University of Bordeaux in France. Among others, the first objectives are to develop a global laser safety program with certification at the European level and a laser-based nuclear radiation safety program. The pedagogical concept will use information technologies. Two types of actions are considered: a library of small programs aiming at simulating complex physical effects occurring in laser or optical devices significantly easing the understanding of the underlying physics. The second action will use the advanced technologies of video games for educational purposes and develop a complete training tool. Trainings will consist in following scenario elaborated by laser physicists to implement in the 3D virtual laser lab the experiment or the optical device.

The objective of the FUNGLASS project is to create a European network in the field of photonics and advanced photonic materials. The challenge is to achieve a scientific goal and to implement an innovative doctoral program which will improve PhD's training and foster their employability. The network will deploy a coordinated strategy and efficient working plan methodology and submitted a proposal to the H2020-Marie Skłodowska-Curie European Training Networks (ETN) call in January 2017. The challenging contribution of FUNGLASS relies on Local functionalization in glass by Laser writing or poling, offering extraordinary opportunity for fabrication of elementary bricks with unique topology, morphology and novel properties for the design of integrated multifunctional components and devices. The R\&D field requires to constitute a consortium of European partners with a very high degree of interdisciplinarity including physicists, chemists, material researchers from high-level research groups and process engineers from both SMEs and large Photonic companies. The ETN project will provide a unique training platform for doctoral research skills in glass-based components and systems for photonics. In addition to the scientific curriculum, the doctoral candidates will be trained in networking, communication and commercial exploitation, preparing them to be the highly skilled workforce in photonics which is penetrating many market sectors.

${ }^{6}$ www.it-elli.org/ 
One of the foundations of the platform is to meet market needs in terms of training. A working group composed of photonics industry (all application sectors) will be set up in order to gather as closely as possible the training needs and recruitment criteria of companies and improve the links between actors in the socio-economic development and education. The working group will be made up of industrials from the photonics domain with the widest possible opening on all topics: materials, aeronautics, health, energy and not only on laser sources. The orientation is to propose a prospective reflection on the research in photonics and the orientations that the trainings must take to train the technicians, engineers and entrepreneurs of tomorrow. The expected outcome is the development of a deliverable of good practices on industrial-university exchanges, analysis of the feasibility of proposals and the proposal of an action plan for initial and in-service training.

In terms of dissemination, the training platform participates in various global dissemination activities such as open days, the CNRS scientific circuit or the Night of Researchers, in order to introduce photonics to the general public and, in particular, to high school students in one of the courses offered on the Bordeaux campus.

The presence at international conferences of pedagogical innovation or bilateral symposia or symposia are also privileged moments of confrontation of points of view and sharing of experience to evolve practices and bring new ideas for the platform, with a goal of continuous improvement.

\section{CONCLUSION AND PERSPECTIVES}

The Optical, Photonics and Laser training platform is now identified as one of the actors for the transformation of the training offer presented by the University of Bordeaux. After a first period of implementation and pilot project developments, the platform entered a development phase with the consolidation of partnerships and projects.

The work to be undertaken for the next period will be to intervene more upstream of the reflections and to propose a disruptive vision based on the excellence of the research and the training needs for the jobs of tomorrow. This phase opens up a number of projects, such as the development of a catalog of research skills and the introduction of interdisciplinary training based on campus strengths.

The various training and research projects come together in the development of a French graduate school with a more fluid training proposal between basic and applied research and the training for master and doctoral degree.

\section{REFERENCES}

[1] David Furió, Martin Hachet, Jean-Paul Guillet, Bruno Bousquet, Stéphanie Fleck, Patrick Reuter, Lionel Canioni, (2015), AMI : Augmented Michelson Interferometer, Talence, France . 